\title{
A case of bone involvement in hairy cell leukemia successfully treated with radiation therapy
}

Article in Tumori · July 2006

Source: PubMed

CITATIONS

2
READS

109

5 authors, including:

Pierfrancesco Franco

Università degli Studi di Torino

124 PUBLICATIONS 686 CITATIONS

SEE PROFILE

\section{Carlo Marinone}

Azienda Ospedaliera Città della Salute e della. .

22 PUBLICATIONS 298 CITATIONS

SEE PROFILE
Andrea Riccardo Filippi

Università degli Studi di Torino

91 PUBLICATIONS 786 CITATIONS

SEE PROFILE

Umberto Ricardi

Università degli Studi di Torino 313 PUBLICATIONS 2,565 CITATIONS

SEE PROFILE

All content following this page was uploaded by Pierfrancesco Franco on 29 November 2016.

The user has requested enhancement of the downloaded file. All in-text references underlined in blue are linked to publications on ResearchGate, letting you access and read them immediately. 


\title{
A CASE OF BONE INVOLVEMENT IN HAIRY CELL LEUKEMIA SUCCESSFULLY TREATED WITH RADIATION THERAPY
}

\author{
Pierfrancesco Franco ${ }^{1}$, Andrea Riccardo Filippi ${ }^{1}$, Alessandro Fornari ${ }^{2}$, Carlo Marinone ${ }^{3}$, and Umberto Ricardi ${ }^{1}$ \\ ${ }^{1}$ Dipartimento di Discipline Medico-Chirurgiche, SCDU Radioterapia, ${ }^{2}$ Dipartimento di Scienze Biomediche ed Oncologia Umana, \\ Servizio di Anatomia Patologica, Università di Torino, Turin; ${ }^{3}$ Medicina Interna, Ospedale S. Giovanni Battista, Turin, Italy
}

\begin{abstract}
We report the case of a 63-year-old man with a clearly established diagnosis of hairy cell leukemia, treated with multiple lines of chemotherapy, who complained of localized pain in the left humerus. Radiological findings showed a distrophicblastic area within the humeral head. Fine-needle biopsy confirmed the hypothesis of bone involvement of hairy cell
\end{abstract}

Key words: bone, hairy cell leukemia, radiotherapy.

\section{Introduction}

Hairy cell leukemia (HCL) was first described in the medical literature at Ohio State University in 1958 by Bouroncle et al. ${ }^{1}$ It is a rare, B-cell lymphoproliferative malignancy, occurring predominantly in men and accounting for $2 \%$ of all leukemias ${ }^{2}$.

HCL has a fairly indolent course, commonly presenting with pancytopenia, bone marrow infiltration, splenomegaly, but mostly without evidence of significant lymphadenopathy. Cytopenias are often severe, particulary anemia and leukopenia, and usuallly lead to the initiation of therapy, causing a high risk of infection. Splenomegaly, which is usually massive, may trigger the diagnostic workup ${ }^{3}$.

Several other uncommon complications have been described in patients affected by hairy cell leukemia, such as meningitis and nerve compression ${ }^{4}$, pleural effusion and ascites ${ }^{5}$ and immunological disorders ${ }^{6}$. Among them, skeletal involvement is a clinically relevant finding for the patient. Localized persisting pain is the leading symptom in the majority of cases. Radiation therapy (RT) has been shown to be effective ${ }^{7}$.

In this paper we present a patient with a destructive bone lesion of HCL involving the left humeral head, which was treated with RT. In addition, we briefly review the available literature on this subject.

\section{Case report}

In 1996, a 54-year-old male carpenter was admitted to the emergency department of our hospital because of prolonged, severe fatigue. He had a clinical history of antibiotic-resolved syphilis and ulcerative peptic disease. He reported weight loss of about $7 \mathrm{~kg}$ during the leukemia. The patient underwent radiotherapy at a dose of 25 Gy, obtaining a complete clinical response with resolution of pain and a partial recovery of the normal radiological structure of the humerus after 2 months. In addition to the case report, we present a short review of the literature focusing on the role of radiotherapy in this subset of patients.

last 60 days and a flu-like episode in the previous month. Laboratory examinations were performed showing the following results: cell blood count (CBC): RBC: $2.23 \times 10^{12} / \mathrm{L} ; \mathrm{Hb} 7.8 \mathrm{~g} / \mathrm{dL}$; MCV: $96 \mathrm{fl} ; \mathrm{MCH}$ : $34.8 \mathrm{pg}$; WBC: $0.96 \times 10^{9} / \mathrm{L}$; ANC: $0.24 \times 10^{9} / \mathrm{L}$; lymphocytes: $620 \times 10^{9} / \mathrm{L}$; monocytes: $110 \times 10^{9} / \mathrm{L}$; eosinophils: $20 \times 10^{9} / \mathrm{L}$; basophils: $10 \times 10^{9} / \mathrm{L}$; platelets: $20 \times 10^{9} / \mathrm{L}$; ESR: $67 \mathrm{~mm} / \mathrm{h}$; total bilirubin: 1.4 $\mathrm{mg} / \mathrm{dL}$; indirect bilirubin: $1 \mathrm{mg} / \mathrm{dL}$.

Bone marrow aspiration failed; bone marrow biopsy showed diffuse interstitial infiltration by CD20+ and DBA44+ lymphocytes, with clear cytoplasm showing a typical HCL pattern. Ultrasonography showed splenomegaly with spleen diameters of 8 and $17 \mathrm{~cm}$. No enlarged lymph nodes were detected at any site. Treatment with interferon alpha- $2 b$ was started at the standard dose of $2 \times 10^{6} / \mathrm{m}^{2}$ IU 3 times a week by subcutaneous injection for 12 months, resulting in normalization of blood parameters lasting for 2 years. In May 1998, disease recurrence was documented and the interferon alpha treatment was resumed until October 2000. This resulted in normalization of $\mathrm{CBC}$ with marked reduction of bone marrow HCL involvement to less than $20 \%$. A second relapse occurred in May 2001. At this time, the patient was given cladribrine $(2 \mathrm{CdA}) 0.09$ $\mathrm{mg} / \mathrm{kg} /$ day, but treatment was interrupted after 1 week because of paroxysmal atrial flutter. In December 2002, treatment with rituximab was started, with once-weekly infusions at $375 \mathrm{mg} / \mathrm{m}^{2} /$ week for 4 weeks, followed by splenectomy a few months later. In December 2003 the patient complained of left arm pain radiating to the ipsilateral shoulder. Plain X-ray film showed a distrophicblastic area in the humeral head and metaphyseal region, without cortical discontinuity. CT and MRI demonstrated a solid mass within the humeral head (5

Correspondence to: Andrea Filippi, Azienda Ospedaliera S. Giovanni Battista, Via Genova 3, 10126 Turin, Italy. Tel +39-011-6336609; fax +39-011-6338680; e-mail andrea.filippi@unito.it 
$\mathrm{cm}$ diameter) and 2 satellite lacunar lesions located on the humerus surgical neck (Figure 1). Bone scintigraphy with ${ }^{99} \mathrm{Tc}-\mathrm{MDP}$ was positive only at that level. Fineneedle biopsy was performed, with a histological finding of hairy cells within the humerus. Examination of the biopsy specimen showed diffuse infiltration of trabecular bone by monomorphic neoplastic elements with oval or indented nuclei and abundant pale cytoplasm. These cells were strongly immunoreactive for CD20 and tartrate-resistant acid phosphatase and showed weak-moderate positivity for CD76 (DBA44) (Figure 2). After performing a complete restaging procedure, we observed no other evidence of disease at the time of bone involvement.

Since the bone pain was worsening, with impaired left arm function, the patient was referred to our radiation oncology department for clinical evaluation. After review of the radiological imaging, the whole humerus was treated with 25 Gy in 10 fractions using parallel opposed fields with 6-MV photons. Substantial pain relief was obtained a few days after the start of RT, and a complete clinical response was observed by the end of the whole treatment. Plain X-ray after 2 months showed partial recovery of the bone structure at the involved site.

\section{Discussion}

Skeletal involvement during HCL is an uncommon, but well described event. The reported incidence ranges

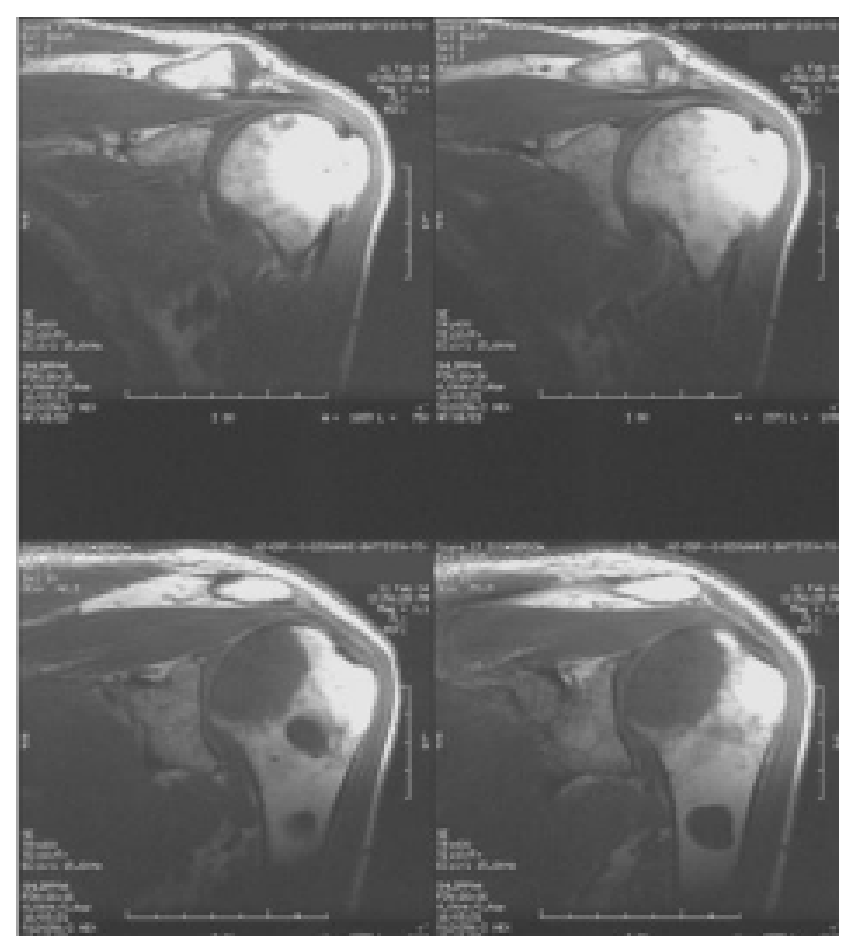

Figure 1 - Circumscribed replacement of the normal bone marrow by patchy areas of low signal intensity on both T1- and T2-weighted MRI images within left humeral head. from $0 \%$ to $13 \%$ in different series ${ }^{8-10}$. Most patients have a previous history of HCL when developing bone lesions; in rare cases bone lesions are the initial disease manifestation leading to the diagnosis ${ }^{11}$. Nevertheless, a presentation as localized skeletal involvement without abnormal peripheral blood counts, splenomegaly or bone marrow infiltration has been described ${ }^{12}$.

Most of these lesions develop in the axial skeleton or in the proximal part of long bones ${ }^{13}$. Commonly involved sites are the femoral head and neck, vertebral column, pelvis, skull, tibia, humeral head and femoral diaphysis ${ }^{7}$. Localized, prolonged pain is the most prominent clinical feature in almost all cases. More rarely there are multiple painful sites, sometimes associated with arthralgia and joint effusion ${ }^{14}$.

Local skeletal lesions can be successfully treated with radiotherapy, achieving rapid and substantial pain relief ${ }^{15}$. Several fractionation schedules and total doses have been reported in published papers. The first report is by Rhyner et al. ${ }^{16}$, who described 3 cases of bone metastases of HCL. Two were irradiated, with a dose of $60 \mathrm{~Gy}$ in one case and of $8 \mathrm{~Gy}$ in a single fraction in the other. In both cases there was resolution of hip pain.

One of the largest series has been described by Lembersky et al. ${ }^{8}$ These authors reviewed the records of 267 HCL patients at the University of Chicago and identified 8 cases of skeletal complications. The latter patients were treated with radiotherapy at doses ranging from $15 \mathrm{~Gy}$ to $30 \mathrm{~Gy}$. In all cases there was symptom improvement. In this series, bone lesions were clearly associated with a large tumor burden, with all patients examined having hypercellular marrow with at least $90 \%$ of the hematopoietic elements being hairy cells. In the paper by Quesada et al. ${ }^{15}, 4$ patients with bone involvement are described. Two of them were treated with radiotherapy (20-25 Gy), with marked pain relief and a complete radiological response in one case. No relationship between skeletal involvement and tumor burden was found by the authors.

The work by Demanes et al. reports 2 cases of HCL with bone lesions ${ }^{11}$. One of these patients was treated with $60 \mathrm{~Gy}$ in 30 fractions. Interestingly, the patient developed aseptic necrosis of the femoral head. The authors conclude that radiation therapy in moderate doses (approximately $5000 \mathrm{rad}$ in 5 weeks) is beneficial in patients with symptomatic or strategically located bone lesions.

From this short overview of the literature it seems clear that there is no general agreement on the best radiation treatment for skeletal localization of HCL in terms of dose and fractionation. If we consider the matter from a radiobiological point of view, low doses are probably sufficient to obtain complete disease control ${ }^{17}$. Leukemic clones of B-cell origin like HCL are extremely radiosensitive, with a surviving fraction after 2 Gy (SF2) in vitro of approximately 0.2-0.3. Taking into account these SF2 values, a dose of 20-25 Gy given with conventional fractionation is theoretically sufficient to reduce a clone of $10^{9}$ cells to 1 . In treating our patient, 


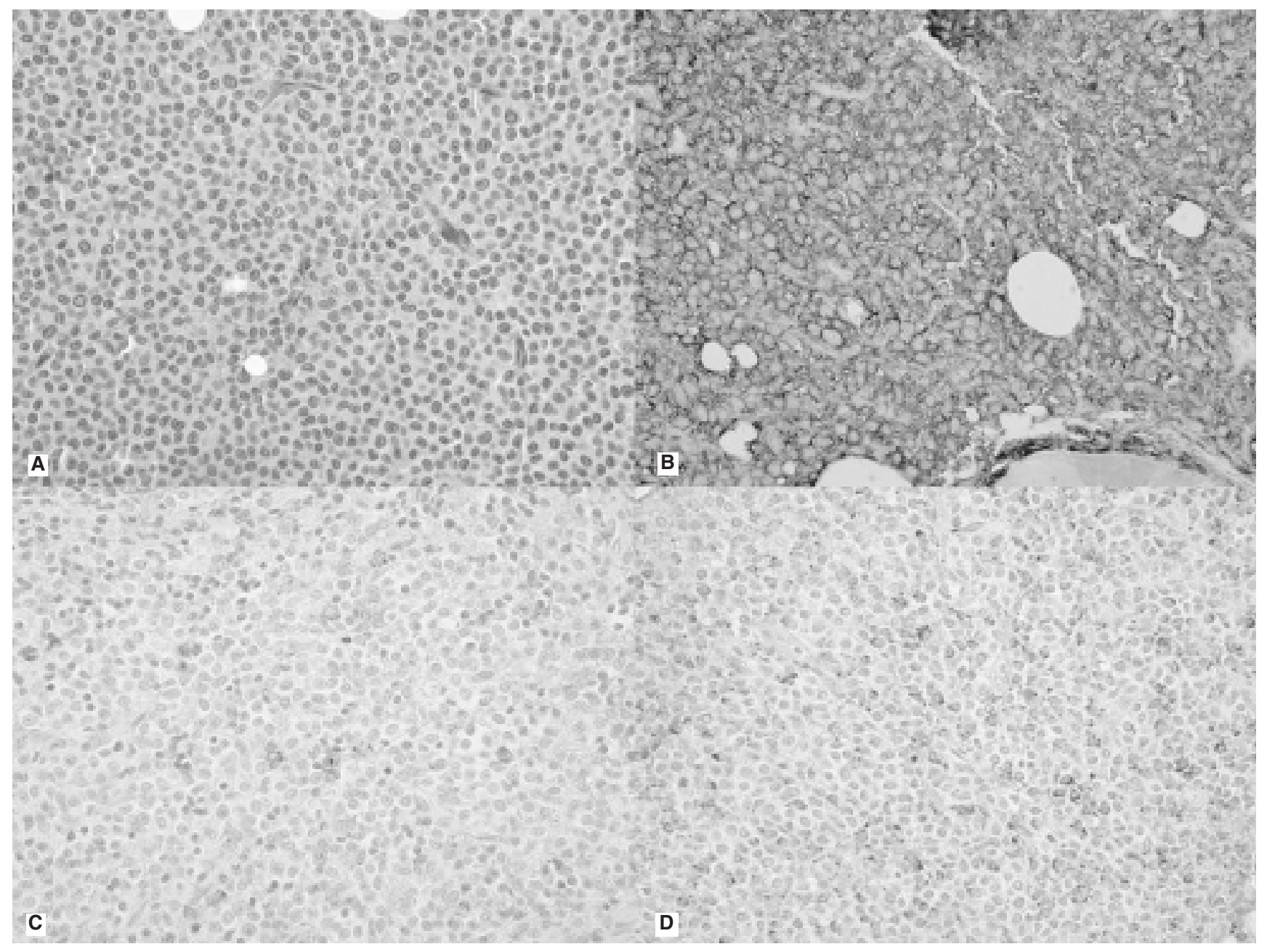

Figure 2 - Hematoxylin and eosin-stained section (original magnification x400) showing infiltration of trabecular bone by neoplastic cells with oval-indented nuclei and abundant cytoplasm. A) Immunohistochemistry showed positivity for B) CD20, C) CD76 and D) tartrate-resistant acid phosphatase (original magnification $\mathrm{x} 400$ ).

we chose a slightly more aggressive fractionation schedule because of the rapid disease progression with extensive humeral involvement and difficult pain control. Low toxicity is expected with this kind of treatment, allowing fractionation to be adapted to the patient's characteristics. In conclusion, since skeletal in- volvement seems not to affect prognosis and since systemic disease can be well controlled with drugs (interferon alpha, pentostatin, cladribine), it is worth treating this kind of patient with eradicating intent (in terms of adequate dose), but with attention to the issue of normal tissue preservation.

\section{References}

1. Bouroncle BA, Wiseman B, Doan CA: Leukemic reticuloendotheliosis. Blood, 13: 609-630, 1958.

2. Bernstein L, Newton P, Ross RK: Epidemiology of hairy cell leukemia in Los Angeles County. Cancer Res, 50: 36053609, 1990.

3. Mey U, Strehl J, Gorschluter M, Ziske C, Glasmacher A, Pralle H, Schmidt-Wolf I: Advances in the treatment of hairycell leukemia. Lancet Oncol, 4: 86-94, 2003.

4. Kimmel DW, Hermann RC, O’Neill B: Neurologic complications of hairy cell leukemia. Arch Neurol, 41: 202-203, 1984.

5. Bouroncle B: Unusual presentations and complications of hairy cell leukemia. Leukemia, 1: 288-293, 1987.
6. Dorsey JK, Penick G: The association of hairy cell leukemia with unusual immunologic disorders. Arch Int Med, 142: 902-903, 1982.

7. Herold CJ, Wittich GR, Schwarzinger I, Haller J, Chott A, Mostbeck G, Hajek PC: Skeletal involvement in hairy cell leukemia. Skeletal Radiol, 17: 171-175, 1988.

8. Lembersky BC, Ratain MJ, Golomb HM: Skeletal complications in hairy cell leukemia: diagnosis and therapy. J Clin Oncol, 6: 1280-1284, 1988.

9. Golomb HM, Catovsky D, Golde DW: Hairy cell leukemia: a clinical review based on 71 cases. Ann Intern Med, 89: 677683, 1978. 
10. Turner A, Kjeldsberg CR: Hairy cell leukemia: A Review. Medicine, 57: 477-499, 1978.

11. Demanes DJ, Lane N, Beckstead JH: Bone involvement in hairy-cell leukemia. Cancer, 49: 1697-1701, 1982.

12. Lal A, Tallman MS, Soble MB, Golubovich J, Peterson L: Hairy cell leukaemia presenting as a localized skeletal involvement. Leuk Lymph, 43: 2207-2211, 2002.

13. Keidan AJ, Liu-Yin JA, Gordon-Smith EC: Uncommon complications of hairy cell leukemia. Br J Haematol, 57: 176$177,1984$.

14. Hudson J, Cobby M, Yates P, Watt I: Extensive infiltration of bone with marrow necrosis in a case of hairy cell leukaemia.
Skeletal Radiology, 24: 228-231, 1995.

15. Quesada JR, Keating MJ, Libshitz HI, Llamas L: Bone involvement in hairy cell leukemia. Am J Med, 74: 228-231, 1983.

16. Rhyner K, Streuli R, Kistler GS: [Hairy-cell leukemia with osteolytic bone changes]. Schweiz Med Wochenschr, 107: 863-871, 1977.

17. Weinmann M, Becker G, Einsele H, Bamberg M: Clinical indications and biological mechanisms of splenic irradiation in chronic leukemias and myeloproliferative disorders. Radiother Oncol, 58: 235-246, 2001. 